\title{
YO! or OY? - say what? Creative place making through a metrolingual artifact in Dumbo, Brooklyn
}

\section{Kellie Gonçalves}

\begin{abstract}
This paper investigates a metrolingual language object and creative place making in Dumbo, Brooklyn within the era of late capitalism. It is an analysis of how two simple letters " $O$ " and "Y", when put together create two short words "OY" and "YO" yet carry exponential meaning about metrolingual language ideologies, language users and powerful social agents. An example of heteroglossic play and linguistic creativity, Deborah Kass's multilingual artwork is at the crossroads of social, cultural, political and linguistic boundaries of diverse communities in urban space. This paper focuses on how the work of one local Brooklyn-based artist was fabricated and re-contextualized for public space, use and consumption, but paid for by a private, influential individual gentrifier and his local real estate development company. In short, it examines a local narrative about key players within urban development schemes driving consumer cultures through unique selling propositions, and thereby laying the foundations for language to emerge and become both a cultural and material artifact reflecting global marketing practices and the semiotic landscaping of urban hubs.
\end{abstract}

\section{Key words: linguistic creativity, metrolingual artwork, language object, gentrification, Brooklyn,}

\section{Introduction}

The study of creativity has a long history within different sub-fields of linguistics.

Since its inception, the field of stylistics has been concerned with language, style and creative deviations of orthographic norms drawing on the foundational work of Jakobson and Halliday in the 1960s and 70s. Most recently, applied linguists, sociolinguists and discourse analysts have focused their attention on creativity as social dynamism, influencing forms of linguistic expression (Carter, 2004, 2016; Pennycook, 2007, 2010; Jones, 2012, 2015) in various contexts, one of which is urban space (Otsuji \& Pennycook, 2010; Pennycook \& Otsuji, 2014, 2015, 2016). According to Thurlow (2012, p. 170) 'creative practice always emerges out of the dialectical tension between fixity and mobility, constraint and freedom, convention and innovation, stricture and defiance, orthodoxy and heterodoxy'. In other words, 
'there is no creative without normative' (ibid.). In order for creativity to be realized, it must therefore always be compared to pre-existing processes within particular contexts since 'creativity does not operate, unbounded, in an autonomous fashion. It is usually shaped by convention'(Negus \& Pickering 2004, p. 68). Just as creativity is dependent on normativity, Harrington maintains that creative processes are products of joint cooperation rather than being viewed as an accomplishment of the individual alone:

Many, and perhaps most, creative accomplishments in this world are neither the products of single individuals working in isolation nor the products of historical geniuses but are instead the products of several people working in intended or unintended collaboration (1990, p. 144).

Collaboration is therefore a prerequisite within the context of creative place-making processes taking place in urban centers globally since such developments result from social, cultural, political, economic and linguistic engagement among individuals, social groups and governing bodies. One type of urban transformation whose political and economic ramifications are discussed in the next section is known as "gentrification", a complex process of urban change that has traditionally been understood to affect different populations and the displacement of individuals from lower socio-economic classes by means of more affluent residents moving to those neighborhoods and bringing their socio-economic capital with them. This paper offers a case study of Dumbo (Down Under the Manhattan Bridge Overpass), which is one of the quickly-gentrifying areas of Brooklyn, a New York City borough witnessing rapid changes in its semiotic landscape (Busse, 2018; Gonçalves 2018; Trinch \& Snajdr 2017). ${ }^{1}$

Originally known as Gairville or Walentasville, Dumbo was renamed in 1978 by a group of artists in an attempt to deter investors. However, following the New York City Streets Renaissance campaign of 2005, Dumbo has become the most

\footnotetext{
${ }^{1}$ Brooklyn is one of the five boroughs along with Queens, Staten Island, the Bronx and Manhattan that make up the metropolitan area known as New York City. At present, Brooklyn is the most populous borough with a resident population of approximately 2.6 million people, compelling Trinch and Snajder (2017) to refer to the borough as a 'city'. In fact, if Brooklyn were a city, it would rank as the fourth largest in the US following New York, Los Angeles and Chicago. See Gonçalves 2018 for a discussion of Bushwick, another Brooklyn neighborhood well known for its street art.
} 
expensive neighborhood in the borough. Recent decades have witnessed the effects of gentrification taking place within Dumbo as a result of various efforts and ensuing actions carried out by regional and local policy-makers, individual gentrifiers and artists in the re-appropriation of space. With a new gentry and what Warf (2000), calls "a new generation flush with exorbitant rewards of the global finance and corporate service industries", which consist of designers, techies and Wall Street types that bring with them specialized shops, stylish restaurants, boutiques, furniture stores and a median income of $\$ 168,000^{2}$. In this version of New York, the streets are made of Belgian cobblestone, and luxury hand-crafted one-bedroom apartments rent for $\$ 4,300$ a month. ${ }^{3}$

In this study, I am particularly concerned with the processes of creative place making by focusing my analysis on the actions of one highly influential gentrifier and Deborah Kass' commissioned multilingual 'language object' (Jaworski, 2015), the OY/YO sculpture, which when viewed from one side reads "OY" and when viewed from the other side reads "YO". As a metrolingual artifact, Kass's temporary artwork quickly became part of New York's cityscape and, in the words of the artist herself, an "instant icon" soon after it was publicly displayed in the newly renovated Brooklyn Bridge Park in 2015. My interest in the semiotic transformation of Dumbo through the re-appropriation of space and the installation of a temporary piece of metrolingual public art have led to the following aims: first, to demonstrate the significance of the sculpture and its placement in creative place making practices of a gentrified neighborhood and second, to specifically investigate the role of metrolingualism as a source of the piece's complex indexicalities and language ideologies.

This study is situated within a broad interdisciplinary theoretical framework of globalization (Blommaert, 2010; Coupland, 2010; Giddens 2003) and mobility (Cresswell, 2006; Sheller \& Urry, 2004; Urry, 2007). It draws on the political economy of place (Molotch, 1976; Logan \& Molotch, 1987, 2007), global marketing practices (Kelly-Holmes, 2010) and adopts a post-structuralist perspective of

\footnotetext{
2 https://www.thenation.com/article/welcome-gilded-city-new-york/

${ }^{3}$ https://www.thenation.com/article/welcome-gilded-city-new-york/
} 
multilingualism (Pennycook, 2010; Otsuji \& Pennycook, 2010; Pennycook \& Otsuji, $2014,2015,2016$ ) shedding light on "how multilingualism is implicated in the arts [...] but "has yet to be explored" (Gardner-Chloros 2014, p. 95).

In an attempt to fuse these theoretical strands together, I begin the paper by discussing the phenomenological approach to place and how creative place making strategies are achieved through the use of unique selling propositions (USP) within global marketing. This is followed by an overview of current sociolinguistic research on multilingualism and metrolingualism in particular. In section 4, I outline my methodology before presenting my analysis of the OY/YO sculpture and interview conducted with Kass. Finally, I discuss my findings and address directions for future research.

\section{Place, Power and Unique Selling Propositions}

Under the 'new' mobilities paradigm, places are considered to be dynamic and in constant flux (Cresswell, 2006; Sheller \& Urry, 2004). Urban landscapes change as different social actors take ownership, control, contest, or abandon spaces (Jaworski 2014, p. 530). For Sheller and Urry places require 'equipping" through signs, walkways and postmodern iconic buildings and are thus viewed as "economically, politically and culturally produced and performed through networked flows of capital, persons, objects, signs and information' (2004, p. 6). Contemporary discussions of space ownership, market flows and urban centers resonate with Molotch's (1976; Logan and Molotch's (1987 [2007]) earlier sociological work on the political economy of place in his investigation of US cities.

For Molotch (1976), the city is regarded as a "growth machine" that serves the interests of land-based elite. Put simply, land-owners invest in their properties in order to reap growth-inducing resources, which contribute to the continuous growth cycle of urban hubs. Governmental authorities, policies and 'privately financed action' (Zukin, 1987) are all utilized in order for development to occur, which serves the interests of both public and private social groups. Conditions of any given locale are therefore "largely a consequence of the social, economic, and political forces" thus underscoring the crucial dimension of social structure and the 
power relations inherent in social class hierarchy (Molotch 1976, p. 309) and neoliberal market forces. In other words, the political economy is at the core of urban growth, a point made well before the 1970s, which continues to hold true into the $21^{\text {st }}$ century (cf. Harvey 2005).

Within any place making context, geographical mobility, the social construction of landscape and marketing strategies (Zukin 2011) must be taken into account, which highlights the socio-political, cultural and economic efforts made by entrepreneurs and local policy makers in their attempt at creating a distinctive, authentic or unique place (Tuan 1977). The notion of uniqueness also emerges within this study and is experienced by individuals through various senses. These include viewing art, living among artists, developers and $21^{\text {st }}$ century dot-commers, within a post-industrial architectural space that indexes Dumbo's historical trajectory, making it distinct from other Brooklyn neighborhoods. For Dumbo is 'not quite Brooklyn brownstone and not quite Manhattan glass condo. With its exposed Belgian block streets anchored by massive bridge structures, Dumbo has a unique character all on its own'. ${ }^{4}$

From a sociolinguistic point of view, the marketability of uniqueness has been highlighted by Kelly-Holmes' (2010) in her study of McDonald's advertising slogan i'm lovin it. Kelly-Holmes borrows two concepts, differentiation and segmentation, both 'at the core of contemporary marketing practice [...] [and] fundamentally linked to language' (Kelly-Holmes 2010, p. 478). The former 'involves the creation of a 'unique selling proposition' '(USP) for a specific product or brand that sets it apart and thus differentiates it from its competitors while the latter 'involves dividing up global markets and consumers in order to create smaller markets that are loyal to this differentiated product or brand' (ibid.). Kelly-Holmes states that the USPs can be regarded as an obsession or even a "fetish" although one that is entirely symbolic and communicated in a variety of ways including endorsement, image, music, celebrity, association and language (ibid.). Within the realm of differentiation, language can be used in a number of ways to distinguish a

\footnotetext{
${ }^{4}$ http://dumbonyc.com/dumbo-history
} 
product and become part of its USP. ${ }^{5}$ Kelly-Holmes maintains that differentiation "frequently involves heteroglossic play, code-switching and mixing, and nonstandard usages" which are associated with individual language practices.

As an urban space and post-industrial neighborhood, Dumbo is at the forefront of late capitalism, where new cultural landscapes of cities are in global competition with one another and gentrification is regarded as a worldwide urban strategy (Smith, 2002). Such processes are 'densely connected into the circuits of global capital and cultural circulation' concerned with capitalist production rather than social reproduction (Lees 2003, p. 2490). In these ways, cities, locales, boroughs and neighborhoods are also branded (cf. Peck \& Banda, 2014) and marketed using effective creative strategies (Richards \& Wilson, 2007), and Brooklyn is no exception (cf. Busse, 2018; Gonçalves 2018; Trinch \& Snajdr, 2017).

Drawing on Kelly-Holmes' work, I maintain that the specific USPs for Dumbo as a place to "stay and play", as its official website claims, works in tandem with various creative place making strategies, one of which is the placement of metrolingual public art in order to reify the area as such. For Grodach et al. creative place making is a 'strategic attempt at place-based, arts-led revitalization' (2014, p. 21) being carried out by both private investors and public bodies in order to bring about neighborhood change. The economic boom of the 1990s coupled with billionaire Mayor Bloomberg's administration re-zoning policies (Brash, 2011) have served as catalysts in the process of New York City reinventing itself as a global lifestyle metropolis, and Dumbo continues to lead the way in Brooklyn. While state and local government officials play a key role in revitalization processes, within the context of this particular neighborhood, Two Trees, the Brooklyn-based, familyowned real estate development-company, has been largely responsible for Dumbo's transformation (Hackworth \& Smith 2001) and "upscaling" (Grodach et al., 2014).

Established in 1968 by David Walentas, the firm has owned, managed and developed a portfolio worth over $\$ 4$ billion USD. Today, it currently manages and owns over 2,000 apartments, and an additional 3 million square feet of commercial

\footnotetext{
${ }^{5}$ Kelly-Holmes talks about the creation of a neologism as a product or even brand name, i.e. ipod (2010, p. 478).
} 
and industrial real estate throughout all of New York City. ${ }^{6}$ The firm has invested in the creative place making of Brooklyn Bridge Park as a prime place to "stay and play" by means of two "artistic dividends 7 ". The first is an installation of a permanent fixture, Jane's Carousel, which cost the Walentas family over $\$ 15$ million USD and was completed in 2011. The second is Deborah Kass's OY/YO temporary metrolingual artifact that was on view in the park from May 2015-August 2016 and became a USP for Dumbo as a prime place for individuals to "stay and play" as part of the work's endorsement, image, celebrity, association and language (see KellyHolmes cited above) in addition to its placement and size.

\section{A planned metrolingual artifact and linguoing}

Much sociolinguistic work problematizes how a language, or languages have been theoretically approached to account for the use of code-mixing, bilingualism and multilingual practices at both the individual and societal level (Heller, 2007; Makoni \& Pennycook, 2006; Auer, 2007). The past two decades have seen a rise in terminology to explain such practices in order to understand how individuals, by drawing on a language, multiple languages or even specific features of a variety to index their socio-cultural and dynamic identities, where meaning emerges, is negotiated and thus contingent on social interaction. ${ }^{8}$ In their seminal work on metrolingualism, which draws on Maher's $(2005,2010)$ conceptualizations of metroethnicity and metrolanguage, Otsuji and Pennycook define metrolingualism as:

the ways in which people of different and mixed backgrounds use, play with and negotiate identities through language; it does not assume connections between language, culture, ethnicity, nationality or geography, but rather seeks to explore how such relations are produced, resisted, defied or rearranged; its focus is not on language systems but on languages as emergent from contexts of interaction. (2010, p. 246, italics my own).

These authors neither renounce nor assume any correlations that exist between language, culture, ethnicity, nationality and geography, but see metrolingualism as a

\footnotetext{
${ }^{6}$ https://twotreesny.com/about-us

7 An "artistic dividend" is considered to be the added value to both regional and local economies through means of artistic work (Markusen \& Schrock 2006, p. 1661).

8 See Pennycook (2016) for a discussion of these terms.
} 
means by which to play with language, which may be interpreted as an instance of creative linguistic performance (Bell \& Gibson, 2011; Jaworski, 2014, 2015). Although the notion of emergence is highlighted in their original definition, which applies to how language, languages or features of a variety are interpreted, I argue that the concepts of temporality and placement must also be considered in the discussion of metrolingual art (Jaworski, 2014) and what I refer to here as a planned metrolingual artifact. ${ }^{9}$

I talk about a planned metrolingual artifact precisely because the notions of temporality and placement of text (Scollon \& Scollon, 2003; Jaworski, 2015) are extremely relevant in any discussion of metrolingual public art. Unlike ephemeral instances of language play that are emergent in social interaction, a metrolingual artifact such as $\mathrm{OY} / \mathrm{YO}$ is the creative outcome of long-time collaborative planning between in this case, an artist, a powerful individual gentrifier, influential local policy makers and public park administrators. All of these people, among many others, have worked together in order to make decisions about the artwork's size and its exact placement in a public space as well as determining the artwork's temporal aspect in terms of how long the piece could legally be displayed in Brooklyn Bridge Park. It will be shown that due to the sculpture's temporality and placement, and ensuing ideologies about language use that are represented and symbolized by the piece itself, the sculpture became a site of playful embodied action by locals and visitors alike.

In their most recent work on linguoing, which will become relevant to the analysis in section 5.3, Pennycook and Otsuji (2016) maintain that despite informants' use of language labels and researchers' attempt at language description, both etic and emic perspectives are necessary in order to account for the disjuncture that exists surrounding the fluidity and fixity of language. They state:

if we work with the labels used by participants in our research [...] while also subjecting such labels to more critical scrutiny, it becomes clear that the terms people use to talk about their multilingual environments are not necessarily as normative as they first appear. Indeed we also find these popular metalinguistic terminologies are flexible, malleable and open to change" (2016, p. 260).

${ }^{9}$ Personal communication with A. Pennycook (March 2017). 
In other words, while language ideologies, rather than users, determine language (Heller 2002), we must be careful to consider how informants talk about language. Doing so may give scholars an insight into the normative language labels individuals employ on the meta level, which may not actually be as rigid and fixed as we think.

\section{Methodology}

This paper is part of an on-going project that began in 2010. The aim of the project is to document and critically examine gentrification processes of various Brooklyn neighborhoods as case studies. Key data consists of photographs of the changing semiotic and geographical landscapes, i.e. signs, construction sites, artwork, etc. In addition, we conducted interviews with residents, developers, historians, business owners and artists. ${ }^{10}$ Interviews lasted between 5-90 minutes. To date, our Dumbo corpus consists of over 3,000 images and over 500 interviews. Here, I draw on data collected in Dumbo with a particular focus on the local Brooklyn-based artist Deborah Kass's metrolingual OY/YO sculpture, which includes a 90-minute interview with the artist conducted in October 2016.

Due to the longitudinal nature of this project, I have observed first-hand the drastic transformation of Dumbo within the last seven years. When I first went there to conduct fieldwork in 2010, Brooklyn Bridge Park was non-existent and a deteriorated waterfront space. Today it is a thriving and dynamic area equipped with various facilities such as bike paths, carousels, and playgrounds that have no doubt come at a considerable cost, both economically and socially. While improvements in a neighborhood may be regarded positively, the negative effects of gentrification drastically affect the displacement of individuals from lower socioeconomic classes (cf. Gonçalves 2018 for a discussion of this in Bushwick).

\section{Data Analysis}

\subsection{Deborah Kass and her metrolingual artifact}

10 This project is being conducted together with Beatrix Busse from Heidelberg University, Germany. 
Deborah Kass is a Brooklyn-based artist acclaimed to be "a pop-culture mastermind" well-known for her "subversive takes on iconic male artists" of the $20^{\text {th }}$ century (Urist, 2016) that include Jackson Pollock, Ed Ruscha, Robert Indiana and Andy Warhol. ${ }^{11}$ Kass's work explores the intersection of the self, art history and pop culture. She is renowned for her use of appropriation and minimalism to make "witty feminist statements" (ibid.) and loud political ones. In the summer of 2016, she created a Warholian portrait of Donald Trump with the words "Vote Hillary" written on the bottom as a fund-raiser for the Clinton campaign, which landed the cover of the New Yorker magazine.

In 2015, Deborah Kass's OY/YO language object and metrolingual artifact made headlines in The New York Times. This was a milestone for Kass, who had until the Two Trees commission never engaged with the production of public art. While the original OY/YO sculpture measured 10 inches by 20 inches and could literally be held in two if not just one hand, the large yellow aluminum sculpture was fabricated into its current dimensions measuring 8 feet tall and 17.5 feet wide in order for its heteroglossic and polyphonic (Bakhtin, 1981) messages to be read all the way from Manhattan and the F.D.R. Drive. ${ }^{12}$

\footnotetext{
${ }^{11}$ https://www.yahoo.com/lifestyle/lenny-interview-deborah-kass-161246937.html?guccounter=1

12 The Franklin D. Roosevelt East River Drive is a 9.5 mile highway that runs along the east side of New York City.
} 
Figure 1. OY view from the park with the Manhattan cityscape in the background.

One glance at the OY sculpture (Figure 1.) in terms of its placement displays a type of semiotic collage with the artwork situated in the foreground and a vibrant cityscape in the background. From this perspective, we encounter the artwork's evident metrolingual appeal while simultaneously viewing the numerous sociopolitical and historical landmarks of the global metropolis. These include various skyscrapers such as One World Trade Center, the main building of the rebuilt World Trade Center that was destroyed on 9/11, the South Street Seaport and the iconic Brooklyn Bridge that spans the East River and connects the boroughs of Manhattan and Brooklyn. From this angle, the background provides the emblematic cityscape of downtown Manhattan of which OY quickly become part. Entering the park, viewers are greeted with "OY", which is widely used in certain British varieties of English to capture individuals' attention. OY is also both a homophone and heterograph of the common Brazilian Portuguese salutation Oi meaning "hi" and the musical subgenre of punk rock known as Oi Punk. ${ }^{13}$ Additionally, OY is a common Yiddish and Lithuanian word expressing dismay and annoyance.

Viewing the sculpture from Manhattan, individuals encounter a very different cityscape with "YO" in the foreground and Dumbo, with its low buildings and emblematic roof top water towers in the background. While not directly underneath the Manhattan Bridge (the longest bridge in the city), Kass's artwork is situated perpendicular to it, highlighting its industrial charm, which has become characteristic of Dumbo within the last decade. From Manhattan, viewers are presented with "YO", which may refer to the Spanish use of "I am", but is also attributed to an informal interrogative or a declarative imperative associated with African-American slang, indexical forms of hip-hop (cf. Pennycook, 2003 on

\footnotetext{
${ }^{13}$ I would like to thank audience members at the Center for the Study of Language and Society (CSLS) at the University of Bern, Switzerland for a great discussion on the meanings and uses of OY.
} 
Japanese 'Rip Slyme') and, increasingly, a common salutation that is a part of the informal register of local and more widespread varieties of English.

Based on a linguistic pun, OY/YO presents viewers and passers-by with a multicultural and multilingual message or 'bilingual wink' (Lamarre, 2014) representing what scholars have called "the double-arrow of indexicality" (Silverstein, 2006; Blommaert, 2013; Jaworski, 2014, 2015). Drawing on the semiotic principle of indexicality ascertains that signs carry information in terms of their producers, their receivers and how they have been previously understood and may continue to be utilized and drawn on precisely because of their ample meaning potential. There is therefore a temporal layering inherent in sign and text production that is regarded as 'being at once repositories of past meanings, and vehicles for future meanings' (Jaworski 2015, p. 79). Indeed Kass's work presents the viewer with an abundance of meaning potential resonating in different languages and speaking to an array of individuals from diverse cultural, linguistic, social, national, ethnic and religious backgrounds. It is an example of metrolingualism and thus creative linguistic play in a specific urban context that is strongly linked to ideologies of societal multilingualism and the right to citizenship regardless of race, class, age or gender.

(Figure 2). YO viewed from Manhattan with Dumbo and the Manhattan Bridge in the background. 
These letters, words and exclamatives are imbued with a particular yet broad symbolism (van Leeuwen, 2001), considering the focus on its form, design and placement. In many ways it is both symbolic and iconic of New York City, a point Kass made directly at the beginning of our interview.

\subsection{Embedding the sculpture in its localness}

Extract (1)

1. Kellie: So you were born in Texas right?

2. Deborah: I was born in Texas, but I'm like a New Yorker, $100 \%$ I'm a total New

3. Yorker my entire family is from New York, so that can give you a little

4. insight into that piece.

In extract 1 Kass utilizes lexical and grammatical repetition (lines $2 \& 3$ ) in order to explain the relevance of being from New York and its symbolic association to her artwork. Although repetition is considered to be 'the central linguistic meaningmaking strategy and a limitless resource for individual creativity' (Carter 2016, p. 101 pharaphrasing Tannen 1989, chapter 3) it also indexes individuals' 'interpersonal involvement' in conversation (Tannen, 1989, p. 52). In addition to signaling her geographic locale and thus regional identity, being a New Yorker signifies a number of socio-cultural and political stances for Kass. Declaring her 
regional and local identity in terms of percentage may symbolize and simultaneously legitimize her artwork as local and authentic.

As a densely populated and mixed urban city that has achieved status as a global power, it may come as no surprise, therefore, that New York City serves as an inspiration for Kass and her artwork. Her declaration of being 100\% New Yorker also suggests that she is quite proud of her "roots" and the place she has called home for 65 years. As a result, Kass's personal history, coupled with New York City's reputation, allows us to potentially comprehend the meaning behind her OY/YO sculpture as a possible extension to her own sense of self (lines $3 \& 4$ ). Since Kass sees New York City as part of her heritage and identity making the sculpture is in some way also autobiographical.

\subsection{OY/YO's cultural and linguistic mediation and negotiation}

The exponential meaning potential inherent in Kass's piece is a salient factor that has contributed to its success as she describes in extract (2):

Extract (2)

1. Deborah: it was embraced so quickly erm so erm to make something that 2. digestable that speaks to so many communities at once you know?

3. that's an ideal and I happen to hit an ideal once and I am so happy that 4. I hit it once

5. Kellie: $\quad$ so when you say that it speaks to so many people on an individual 6. level but also on a collective level in terms of communities or specific 7. socio-cultural groups, can you expand on that?

8. Deborah: well obviously it's in a lot of languages and that's ... that's it and that 9. was the, that was a kind of struck of luck seeing OY reflected in a 10. window and it said "YO" it was just one of those crazy, lucky things, 11. everything about this to use the Yiddish word was beshared and I'm 12. not particularly Jewish but that word really works here and it, you 13. know, I was there when over the summer a group of Hasidic school 14. girls, like, their summer camp or something and their teacher was like 15. 20 and I'm quite certain that's the first time they've seen their 16. reflection in a work of art and I will tell you, they are so segregated 17. from the rest of New York City, they didn't know what YO meant 18: Kellie: really?

19. Deborah: yes, they live in a neighborhood, Crown Heights is a famous black and 20. Hasidic community and the teacher said, "what's YO mean, is that 

God, I don't know exactly what her reference was but I went, "No, it's

23. like YO, hello, like, Italian kids, black kids, all kids who aren't Hasidic

24.

25. say YO instead of hey, instead of hello it's YO, YO, YO" she had no idea and that was the teacher

The dialogical work of the original piece is proclaimed by Kass to be a "struck of luck" (line 9) rather than an intended instance of planned metrolingual play. The inherent multilingualism found within it (line 8), is not only obvious as Kass suggests, but the main reason for the piece's popularity and individuals' ability to connect with it (line 2) since it draws on multiple voices from different communities. These factors are what compel Kass to describe the sculpture as "beshared" (line 11).

During the time of OY/YO's installation, Kass regularly visited her work and, on multiple occasions, talked with individuals engaging with the sculpture. The example she describes in extract (2) refers to her encounter with a group of local Hasidic Jewish girls who had gone to OY/YO during a summer camp excursion. The fact that the 20 year-old teacher did not know the meaning of YO (line 17) is explained by Kass as a result of their strict orthodox religion and societal segregation (line 16). Crown Heights is a well-known community with a large population of Caribbean immigrants and home to the world headquarters of the Lubavitcher Hasidim Movement. While this group of girls as Kass explains are not aware of YO's widespread usage (line 23), they could relate to OY, its Yiddish counterpart (lines $15 \& 16$ ).

This example highlights how this particular instance of language becomes mediated by the social ways in which it is viewed and as such exemplifies how metrolingual ideology is negotiated. This becomes clear in Kass's response to the teacher's question, "No, it's like YO, hello, like, Italian kids, black kids, all kids who aren't Hasidic say YO instead of hey, instead of hello it's YO, YO, YO" (lines 20-25). For Kass, the use of $\mathrm{YO}$ in this context is reserved for youth, and its usage cuts across cultural, ethnic, national, racial, geographic and social boundaries. Kass's repetitive use of both kids and $Y O$ functions to emphasize the evaluative point she is trying to make to the young Jewish teacher. In addition to listing local and, to some extent, 
even widespread (line 23) and thus global categories of language description, Kass is simultaneously engaging in a modern language ideological lesson.

\subsection{Visitors' self emplacement with metrolingual artwork}

The monumental and multimodal OY/YO sculpture was Kass's first engagement with public art. Its large dimensions, strong typographic resonance with pop art of the 1960s and exact placement between the Brooklyn and Manhattan bridges were key factors that assisted in making the piece iconic and a playful site for embodied action:

Extract (3)

1. Deborah: I mean, it was like crazy, how intensely people interacted with this

2. and it really became a landmark, instantly, so, but it's because it

$3 . \quad$ spoke, literally spoke to so many people

4. Kellie: $\quad$ were you expecting this at all?

5. Deborah: well, when it went up, you know? I am a student of post-war art and

6. know my stuff and I really know pop and I really know minimalism

7. and it's one thing to see this thing in 10 inches by 20 , but when it was

8. installed, the minute it went into the ground, you know, I texted my

9. wife and I said, "instant icon" you know? this is everything I love in

10. one place, this is multi, this is "I love new york" meets Indiana, meets

11. pop, meets minimalism, meets multiculturalism", this is everything I

12. care about and so I was not ... yeah, I've never seen a reaction to this,

13. I'm gonna be 65, I've been in New York my whole life, I've actually

14. never seen a reaction like this to a piece of art

In addition to the linguistic performance of the sculpture, Kass attributes its size and her use of appropriation and thus re-contextualization (Bauman, 2001; Bauman \& Briggs, 1990; Jaworski, 2012, 2015) of previous pop art, which led to its landmark status. This becomes clear when she states "this is everything I love in one place" (lines $9 \& 10$ ) and continues by listing the specific imagery, iconography, logos and style employed that is associated with post-war art of the 1960s and 70s. First she states, "this is I love New York meets Indiana". Here, Kass draws on the New York City trademarked logo in figure 3, which has been owned by the New York State 
Department of Economic Development since 1977, when it was used as the basis of an advertising campaign to promote tourism within New York City. ${ }^{14}$

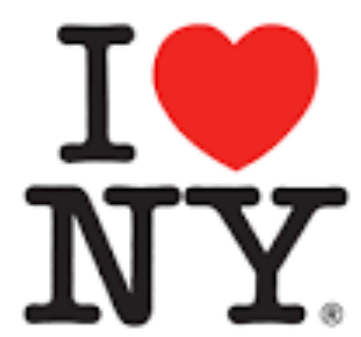

Figure 3. I love NY trademarked logo.

The logo consists of a capital letter I followed by a red heart symbol, and the capital letters $N Y$ below. The letters are all set in a rounded slab serif typeface known as "American Typewriter". Next, Kass makes reference to pop artist Robert Indiana, who created 'one of the most recognizable artworks of the twentieth century, his LOVE letter design' (Jaworski, 2015, p. 85). Jaworski maintains that 'it was probably Pop Art in the 1960s that brought language as an autonomous mode of expression in art to broader public attention' (Jaworski, 2015, p. 84). Within the context of this study, Kass utilizes language in an unconventional, creative and playful way in order to make a statement that captured the attention of locals and international visitors to Dumbo and the greater New York City area. In fact, soon after its placement, OY/YO became a tourist site included on the New York City Circle Line Sightseeing Tour leading Kass to call it an "instant icon" (line 9). ${ }^{15}$

The public's fascination with the sculpture was, however, rather unexpected (lines 12-14). As a piece of public art, its fabrication was initially intended for public view only, but within days of its appearance and largely due to its size and proportioned dimensions, it became a site for individuals to engage in physically

\footnotetext{
${ }^{14}$ http://www.logoworks.com/blog/a-brief-history-of-the-i-love-new-york-logo/

15 The New York City Circle Line Sightseeing Cruise Tour offers several different packages for visitors to see famous landmarks, which include, for example, the Statue of Liberty, the Empire State Building, One World Trade Center, and United Nations, Columbia University and Yankee Stadium to name a few.
} 
and have a corporeal and thus embodied experience (Edensor 1998; Jaworski \& Thurlow, 2011; Thurlow \& Jaworski, 2014) as Kass describes below:

\section{Extract (4)}

1. Kellie: but did you have this idea in mind that people were going to be

2. playing with it?

3. Deborah: I had no clue, that freaked me out, I went the first day when we put it 4. up, I went back there erm it was installed on a Tuesday and I went on 5. a Saturday and I lost it, I was so freaked out, people were on it, it was 6. already scuffed, thinking, someone's gonna really hurt themselves and 7. at that point there wasn't any signage like "keep off of it" or anything 8. so there are signs [now] but nobody pays attention, so I was really 9. freaked out, I was like someone's gonna kill themselves this is bad, 10. somebody's gonna get hurt, on top of that, it was getting scuffed you 11. know? so they, like I freaked, I got over it, the head of the Brooklyn 12. Bridge Park was like "really, you didn't think people would crawl on 13. it?" and I said, "it never really occurred to me, I never even considered 14. that people would, would crawl on it ... erm, no"

15. Kellie: $\mathrm{mhm}$

16. Deborah: then I got into it as one would and I was like "well, this is kind of 17. amazing"

Despite Kass's original intention for $\mathrm{OY} / \mathrm{YO}$ as a site to be viewed, consumed and gazed upon, it quickly became a site of embodied action, where multimodal discursive practices were being played out, which is attested to in the images of the sculpture found on Kass's website. ${ }^{16}$ The fact that individuals were crawling on Kass's artwork four days after its installment reveals the rather intricate representational and interactional meaning and work being done by OY/YO visitors. Indeed there was no signage initially informing visitors to "keep off" the piece (line 7); however, when signs were positioned, they were simply ignored (line 8). In this way, the public was also being unconventional by not "playing by the rules" or engaging in normative behavior, which indexes a form of creative embodied action through their playful and physical interaction with the artifact.

What is striking in this extract is the differing opinions between Kass and the

\footnotetext{
${ }^{16}$ An online search of the OY/YO sculpture also renders several pictures of individuals physically engaging with the piece. (https://deborahkass.com).
} 
head of Brooklyn Bridge Park, which is reconstructed through reported speech and in this instance functions to convey the accuracy and authenticity of the actual storytelling event (Holt, 2000). While Kass never considered peoples' physical and embodied engagement with the piece, the head of the park certainly did (lines 12 \& 13) and leads one to speculate about the degree of embodied action and physical play desired from Two Trees, who commissioned the artwork. Subsequent to Kass's shock and being "freaked out" (lines 3,5,11), over time and through self-reflection, she eventually embraced it (line 16) asserting such playful performances as "amazing" (line 17). Through embodied action and such playful enactments by OY/YO visitors, individuals were discursively creating their own sense of self while simultaneously creating a sense of place as a site to "stay and play".

\section{Conclusion}

In this study I have examined the process of creative place making by focusing on a metrolingual artifact in Dumbo, Brooklyn that is highly influenced by neoliberal urban policies within late capitalism. Adopting a post-phenomenological approach to place means that, places are never finished but always in transition and in the process of becoming. With the becoming of Dumbo, vital local agents are at play, such as Two Trees' engagement in the major semiotic transformation of the neighborhood by equipping Brooklyn Bridge Park with an 'artistic dividend' such as Kass's OY/YO metrolingual sculpture through their joint collaboration. Although the price of its fabrication was never revealed and a point Kass wished not to comment on, it is known that Two Trees paid for the entire fabrication and would also profit from its subsequent sale.

I have shown that within the realm of global marketing practices Two Trees has utilized Kass's OY/YO as a USP for Dumbo and Brooklyn Bridge Park in particular by means of various forms of differentiation that include endorsement, image, celebrity and language. The fact that Two Trees commissioned Kass, a local Brooklyn-based celebrity artist, may come as no surprise since they have an extensive track record of supporting creative and community-based tenants in 
order for successful neighborhoods to be attractive while simultaneously cultivating livable streetscapes by funding amenities such as parks and cultural spaces. ${ }^{17}$ Placing Kass's metrolingual sculpture in the park without initial signage may have been Two Trees intention in order for visitors to physically engage with the piece (although this is mere speculation), which resulted in the artwork's popularity, Dumbo's image and landmark status as well as its ensuing artistic dividends for the local community, but ultimately Two Trees.

Kass's metrolingual and multimodal artwork is an example of a linguistic performance and thus heteroglossic play made by Kass and experienced by visitors alike who have been able to personally, psychologically and physically connect with the piece since it symbolizes the cultural melting pot of New York City and perhaps Brooklyn in particular (albeit without the 'melting' of young Hasidic Jewish girls) by indexing values of authenticity, cultural diversity, and a sense of community. Drawing on the notion of metrolingualism has allowed me to show the 'paradoxical practice and space where fixity, discreteness, fluidity, hybridity, locality and globality [...] coexist and constitute each other' (Otsuji \& Pennycook 2010: 252) within a piece of displayed public art. Such paradoxical practices of language use emerged in my discussion of linguistic and creative play with the OY/YO artifact that was very much planned over years despite its temporary installment in Brooklyn Bridge Park. Metrolingualism is a useful concept in any discussion of heteroglossic play and linguistic creativity that is found at the crossroads of social, cultural, political and linguistic boundaries of diverse communities in urban space that extend beyond purely ephemeral language practices to account for planned linguistic ones, where rather unexpected reactions occurred. Indeed the linguistic creativity inherent in the OY/YO sculpture that was originally embedded on a local scale transpired into regional and even widespread global interpretations, remediations and recontextualizations of it exemplifying the ways in which 'different language resources are drawn on for different effects' (Pennycook 2010: 133).

17 https://www.twotreesny.com 
In addition to investigating Kass's metrolingual object, I also analyzed extracts from my interview with Kass. Talking to Kass about her piece highlighted the linguoing taking place at the meta level of conversation. Ways in which Kass spoke about OY and YO with the example of the Hasidic group of Jewish girls allowed me to uncover her emic perspective of language and metrolingual ideologies by drawing on normative labels such as Italian and black, which are not static, but fluid and cut through national, ethnic, racial, linguistic, religious and geographical boundaries.

There is no doubt that Dumbo's transformation including the newly semiotized Brooklyn Bridge Park has been drastically affected by gentrification processes that have and continue to take place across the entire regional landscape. ${ }^{18}$ However, due to its proximity to Manhattan, its key waterfront location, historical industrial architecture coupled with neoliberal re-zoning policies and Two Trees capital investment, the speed and shifts of this neighborhood's revitalization as a New York City hotspot and prime place to "stay and play" is, as Curran suggests, "an inevitable outcome of global competition but also a result of speculative real estate pressure that is tied directly to gentrification" (2007, p. 1428). In other words, creative place making and industrial displacement is not simply an "unfortunate consequence" of the revitalization of the inner city, but "an active process undertaken by real estate developers, city planners, policy-makers, landlords and even individual gentrifiers" (ibid.;). With these points in mind, Dumbo cannot be regarded as an unexpected place to play, but the result of precise and orchestrated planning by some of the most powerful social agents in New York City.

With the creation of any city or neighborhood there is indeed a need to engage with difference. Despite the socio-economic differences present in New York City, Brooklyn and Dumbo, this study has shown that the re-appropriation of 'public' space is perhaps not all that 'public' but connected to current values of innovative capitalist production due to gentrification processes and arts-lead revitalization movements that individual gentrifiers are financing and profiting from in order to

${ }^{18}$ Cf. Curran's (2007) study on gentrification and industrial displacement in Williamsburg, Brooklyn. 
maintain "growth machines". Future studies investigating the connection between multilingualism and the arts or creative place-making strategies by means of artwork concerning the re-appropriation of space and semiotic landscaping of urban centers need to consider the active processes of space ownership among specific powerful social agents more closely. Indeed, influential elite society members and land-owners are the ones responsible for space management and decisions about creative practice and thus convention and innovation while also directly benefitting from artistic dividends that they initially support. As a result, they are the ones equipped with the economic means and socio-political power to transform geographic spaces into creative ones. Within the context of Dumbo, the collaborative efforts of creating a multimodal and semiotic language object imbued with metrolingual symbolism altered a local neighborhood into a global landscape as a place to visit, stay or simply play.

This work was supported by the Research Council of Norway through its Centres of Excellence funding scheme, project number 223265.

\section{Acknowledgments}

A special thanks to Deborah Kass for taking the time to talk to me about her artwork. I would like to thank both Mairéad Moriaty and Johan Järlehed for their superb editorial guidance and patience. And finally, thank you to thank Adam

Jaworski, Anne Schluter, Rafael Lomeu Gomes, Robert Blackwood, Kristin Vold Lexander, Alastair Pennycook and two anonymous reviewers for their comments on earlier drafts of this paper. Any errors and shortcomings are my own.

\section{References}

Auer, P. (2007). The monolingual bias in bilingualism research, or: Why bilingual talk is (still) a challenge for linguists. In M. Heller (Ed.), Bilingualism: A social approach (pp. 319-339). London, UK: Palgrave Macmillan.

Bakhtin, M. M. (1981). The dialogic imagination: Four Essays. M. Holquist (Ed.), C. Emerson \& M. Holquist (tr.). Austin, TX: University of Texas Press. 
Bauman, R. \& Briggs, C. (1990). Poetics and performance as critical perspectives on language and social life. Annual Review of Anthropology, 19, 59-88.

Bell, A. \& Gibson, A. (Eds.). (2011). The sociolinguistics of performance. Special issue of the Journal of Sociolinguistics, 15, 627-656.

Blommaert, J. (2010). The sociolinguistics of globalization. Cambridge, UK: Cambridge University Press.

Blommaert, J. (2013). Ethnography, Superdiversity and Linguistic Landscapes: Chronicles of complexity. Bristol: Multilingual Matters.

Brash, J. (2011). Bloomberg's New York. Athens, Georgia: University of Georgia Press. Busse, B. (2018, forthcoming). Patterns of discursive urban place-making in Brooklyn, New York. In Wiegand, V., Mahlberg, M. (Eds.), Corpus Linguistics, Context and Culture. Berlin: de Gruyter and Mouton.

Carter, R. A. (2004). Language and Creativity: The art of common talk. London: Routledge.

Carter, R. A. (2016). Language and Creativity: The art of common talk. Second edition. London: Routledge.

Cresswell, T. (2006). On the Move: Mobility in the Modern Western World. New York: Routledge.

Curran, W. (2007). 'From the Frying Pan to the Oven': Gentrification and the Experience of Industrial displacement in Williamsburg, Brooklyn. Urban Studies, 44, 1427-1440.

Gardner-Chloros, P. (2014). Multilingualism and the arts: Introduction. International Journal of Bilingualism 18, 2, 95-98.

Giddens, A. (2003). Runaway World: How Globalisation is Reshaping our Lives. New York: Routledge.

Gonçalves, K. (2018). The Semiotic Paradox of Street Art: Gentrification and the Commodification of Bushwick, Brooklyn. In Peck, A., Williams, Q. and C. Stroud (Eds.), Making sense of people, place and linguistic landscapes. London: Bloomsbury.

Grodach, C., Foster, N. \& Murdoch, J., III. (2014). Gentrification and the Artistic Dividend: The Role of the Arts in Neighborhood Change. Journal of the 
American Planning Association, 80, 1, 21-35.

Hackworth, J. \& N. Smith. (2001). The Changing State of Gentrification. Tijdschrift voor Economische en Sociale Geografie 92, 4, 464-477.

Harington, I. (1990). The ecology of human creativity. In Runco, M. and Albert, R. (Eds.), Theories of Creativity. London: Sage. Pp. 143-169.

Harvey, D. (2005). A Brief History of Neoliberalism. New York: Oxford University Press.

Heller, M. (Ed.). (2007). Bilingualism: A Social Approach. London: Palgrave Macmillan.

Jaworski, A. (2014). Metrolingual art: Multilingualism and heteroglossia. International Journal of Bilingualism 18, 2, 134-158.

Jaworski, A. (2015). Word cities and language objects: 'Love' sculptures and signs as shifters. Linguistic Landscapes 1,1-2, 75-94.

Jaworski, A. \& Thurlow, C. (Eds.). (2010). Semiotic landscapes: Language, image, space. London, UK: Continuum.

Jaworski, A. \& Thurlow, C. (2011). Tracing place, locating self: Embodiment and (re)mediation in/of tourist spaces. Visual Communication, 10(3), 349-366.

Jones, R. (Ed.). (2012). Discourse and Creativity. London: Pearson.

Jones, R. (Ed.). (2015). The Routledge Handbook of Language and Creativity. New York: Routledge.

Kelly-Holmes, H. (2010). Languages and Global Marketing. In N. Coupland (Ed.), Handbook of language and globalization (pp. 475-492). Oxford, UK: WileyBlackwell.

Lamarre, P. (2014). Bilingual winks and bilingual wordplay in Montreal's linguistic landscape. International Journal of the Sociology of Language, 228, 131-151.

Lees, L. (2003). Super-gentrification: The Case of Brooklyn Heights, New York City. Urban Studies 40, 12, 2487-2509.

Logan, J.R. and Molotch, H.L. (1987 [2007]. Urban fortunes: the political economy of place. Berkeley \& LA: University of California Press.

Maher, J.C. (2005). Metroethnicity, language, and the principle of Cool. International Journal of the Sociology of Language, 175/176, 83-102. 
Maher, J.C. (2010). Metroethnicities and metrolanguages. In N. Coupland (Ed.), Handbook of language and globalization (pp. 575-591). Oxford, UK: WileyBlackwell.

Makoni, S. \& Pennycook, A. (2006). Disinventing and Reconstituting Languages. Bristol: Multilingual Matters.

Negus, K. \& Pickering, M. (2004). Creativity, communication and cultural value.

Molotch, H.L. (1976) The city as a growth machine. American Journal of Sociology 75, 226-238.

Peck, A. \& Banda, F. (2014). Observatory's linguistic landscape: semiotic appropriation and the reinvention of space. Social Semiotics 24, 3, 302-323.

Otsuji, E. \& Pennycook, A. (2010). Metrolingualism: Fixity, fluidity and language in flux. International Journal of Multilingualism, 7, 240-254.

Pennycook, A. (2003). Global Englishes, Rip Slyme and performativity. Journal of sociolinguistics 7,4, 513-533.

Pennycook, A. (2007). 'The Rotation Gets Thick. The Constraints Get Thin': Creativity, Recontextualization, and Difference. Applied Linguistics 28, 4, 579596.

Pennycook, A. (2010). Language as a Local Practice. Abigdon, UK: Routledge

Pennycook, A. (2016). Mobile times, mobile terms: The trans-super-poly metro movement. In Coupland, N. (Ed.), Sociolinguistics: Theoretical Debates. (pp. 201-216). Cambridge: Cambridge University Press.

Pennycook, A. \& Otsuji, E. (2014). Market lingos and metrolinga francas. International Multilingual Research Journal 8, 4, 255-270.

Pennycook, A. \& Otsuji, E. (2015). Metrolingualism: Language in the city. London: Routledge.

Pennycook, A. \& Otsuji, E. (2016). Linguoing, language labels and metrolingual practices. Applied Linguistics Review 7, 3, 259-277.

Richards, G. \& Wilson, J. (Eds.) (2007). Tourism, Creativity and Development. New York: Routledge.

Scollon, R. \& Wong Scollon, S. (2003). Discourses in place: Language in the material world. London: UK: Routledge.

Sheller, M. \& Urry, J. (Eds.) (2004). Tourism Mobilities: Places to Play, Places in Play. 
New York: Routledge.

Silverstein, M. (2006). How We Look from Where We Stand. Journal of Linguistic Anthropology, 16, 2, 269-278.

Smith, N. (2002). New globalism, new urbanism: gentrification as a global strategy, Antipode, 34 427-450.

Tannen, D. (1989). Talking Voices : Repetition, Dialogue, and Imagery in Conversational Discourse. Cambridge \& New York: Cambridge University Press.

Thurlow, C. (2012). Determined creativity: Language play in new media discourse. In R. Jones (Ed.), Discourse and Creativity (pp. 169-190). London: Pearson

Thurlow, C. \& Jaworski, A. (2014). 'Two hundred ninety-four': Remediation and multimodal performance in tourist placemaking. Journal of Sociolinguistics, $18,4,1-40$.

Trinch, S. \& Snajdr, E. (2017). What the signs say: Gentrification and the disappearance of capitalism without distinction in Brooklyn. Journal of Sociolinguistics 21, 1, 64-89.

Tuan, Yi-Fu. (1977). Space and Place: The Perspective of Experience. Minneapolis: University of Minnesota Press.

Urry, J. (2007). Mobilities. Cambridge: Polity.

Van Leeuwen, T. (2001). Semiotics and iconography. In Van Leewen, T. and C. Jewitt (eds.). The Handbook of Visual Analysis. London, Sage. Pp.92-118.

Warf, B. (2000). New York: the Big Apple in the 1990s. Geoforum, 31 487-499.

Zukin, S. (1987). Gentrification: Culture and capital in the urban core. Annual Review of Sociology 13, 129-147.

Zukin, S. (2011). Reconstructing the authenticity of place. Theory and Society 40, 161-165. 
